\title{
First report of wheat stripe mosaic virus in Paraguay
}

\author{
Arnaldo Esquivel-Fariña ${ }^{1}$ (D) - Viviana M. Camelo-García ${ }^{1}$ - Elliot W. Kitajima ${ }^{1}$. \\ Jorge A. M. Rezende ${ }^{1} \cdot$ Luis R. González-Segnana $^{2}$
}

Received: 11 June 2019 / Accepted: 8 July 2019 / Published online: 15 July 2019

(C) Australasian Plant Pathology Society Inc. 2019

\begin{abstract}
Soil-borne viruses transmitted by Polymyxa graminis can lead to major yield losses in wheat crops worldwide. This work describes the identification of a soil-borne virus infecting wheat plants in Paraguay. Based on electron microscopy observations of virus particles in symptomatic leaf and molecular assays the virus was identified as wheat stripe mosaic virus (WhSMV). To our knowledge, this is the first report of WhSMV in Paraguay.
\end{abstract}

Keywords Wheat $\cdot$ Soil-borne virus $\cdot$ Diagnose

Wheat (Triticum spp.) cultivation in Paraguay has experienced a boom in production in the last two decades (FAO 2017). Currently, wheat is the most important crop during the winter season in the southeastern region of the country. In June 2016, randomly irregular patches of wheat plants (var. Itapúa 65) exhibiting streaking mosaic on the leaves and stunting (Fig. 1a, b) were observed in an experimental field at the Paraguayan Institute of Agricultural Technology (IPTA), located in the district of Capitán Miranda, Itapúa Department, Southeast of Paraguay. Negatively stained leaf extract of symptomatic wheat leaves examined in the transmission electron microscopy revealed the presence of rod-shaped like-virus particles (Fig. 2a), similar to those belonging to the genera Benyvirus and Furovirus, which are transmitted by the soil-borne plasmodiophorid Polymyxa graminis (Kanyuka et al. 2003). The presence of resting spores of $P$. graminis in the root of symptomatic wheat plants was confirmed by optical microscopy using the lactophenol

Arnaldo Esquivel-Fariña

arnaldo.esquivel@usp.br

1 Departamento de Fitopatologia e Nematologia, Universidade de São Paulo, Piracicaba, Brazil

2 Departamento de Biología, Universidad Nacional de Asunción, San Lorenzo, Paraguay staining technique (Fig. 2b). Total RNA extraction was performed on leaves and roots of six symptomatic wheat plants using Plant RNA purification reagent (Thermo Fisher Scientific, Waltham, USA) following the manufacturer protocol. RT-PCR was performed using specific primers for soil-borne wheat mosaic virus (SBWMV) and wheat spindle streak mosaic virus (WSSMV) (Clover and Henry 1999; Clover et al. 2001), which are found worldwide associated with soil-borne wheat diseases, but no replicons were amplified. Specific primers for wheat stripe mosaic virus (WhSMV), which was recently described associated with soil-borne wheat mosaic disease in South of Brazil (Valente et al. 2019), was also used for RT-PCR. Amplicons of expected size for WhSMV were obtained from total RNA extracted from all symptomatic samples using primers Beny_Pol-F (5'-ATCGATGCTGACGC TTTCACTG -3') and Beny Pol-R (5'-ACGAAACA CCTGTGTCGCTA $-3^{\prime}$ ) and primers Beny_CP-F (5'AAGTGTCGCAAGCTTCGCG-3') and Beny_CP-R (5'ATCGCACCGACGTAAGAACT-3'), which enables the amplification of genomic regions of $465 \mathrm{bp}$ and $641 \mathrm{bp}$, corresponding to part of the replicase protein gene and the complete CP gene, respectively (Valente et al. 2019). All amplicons were purified and directly sequenced in both directions at Macrogen Inc. (Seoul, South Korea). The consensus nucleotide sequences were obtained using the Electropherogram quality analysis program (http:// asparagin.cenargen.embrapa.br/phph/). Deduced amino acid sequences were obtained using ExPASy (https://web. 

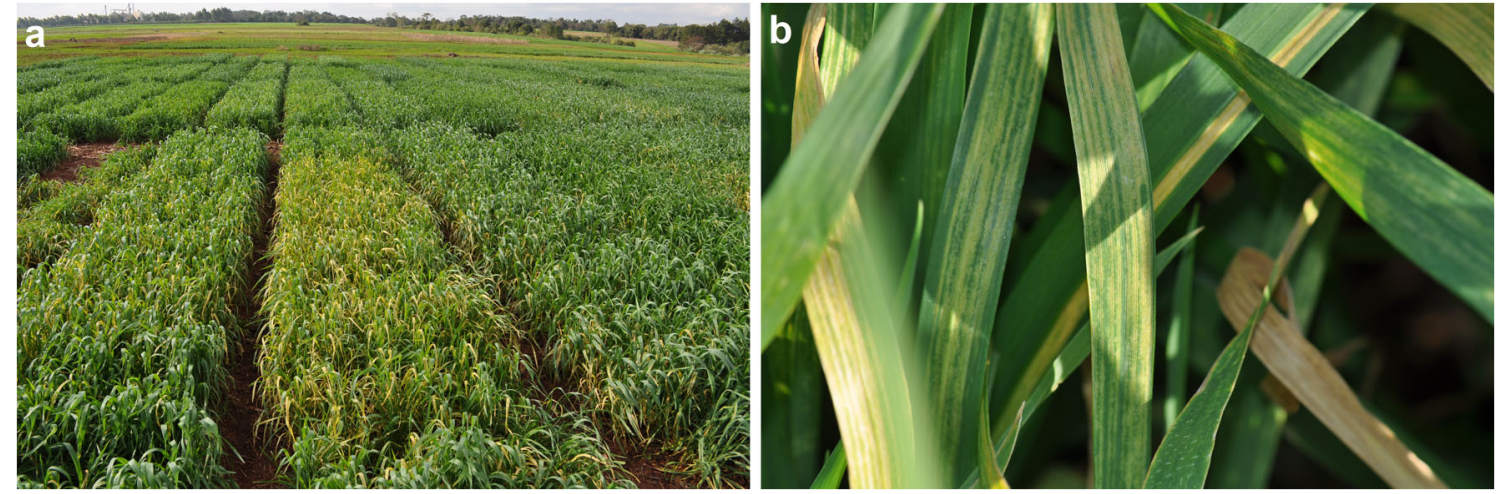

Fig. 1 a Chlorotic patches of infected plants in the experimental field. b Symptoms of Wheat stripe mosaic virus on leaves of wheat

expasy.org/translate/) and aligned using Clustal Omega (https:/www.ebi.ac.uk/Tools/msa/clustalo/). Amino acid sequences of the replicase protein (MK994524) and CP (MK994525) showed $100 \%$ and $96.55 \%$ to $98.85 \%$ identity, respectively, with corresponding protein sequences of WhSMV from Brazil (Replicase protein MH151795 MH151800; CP MH151801 - MH151805), a putative new member of the family Benyviridae. To our knowledge, this is the first report of a virus associated with a soil-borne wheat mosaic disease in Paraguay. Further surveys are necessary to determine the occurrence and economic impact of WhSMV in commercial wheat crops throughout the country.

\section{References}

Clover G, Henry C (1999) Detection and discrimination of wheat spindle streak mosaic virus and wheat yellow mosaic virus using multiplex RT-PCR. Eur J Plant Pathol 105(9):891-896

Clover G, Ratti C, Henry CM (2001) Molecular characterization and detection of European isolates of soil-borne wheat mosaic virus. Plant Pathol 50(6):761-767
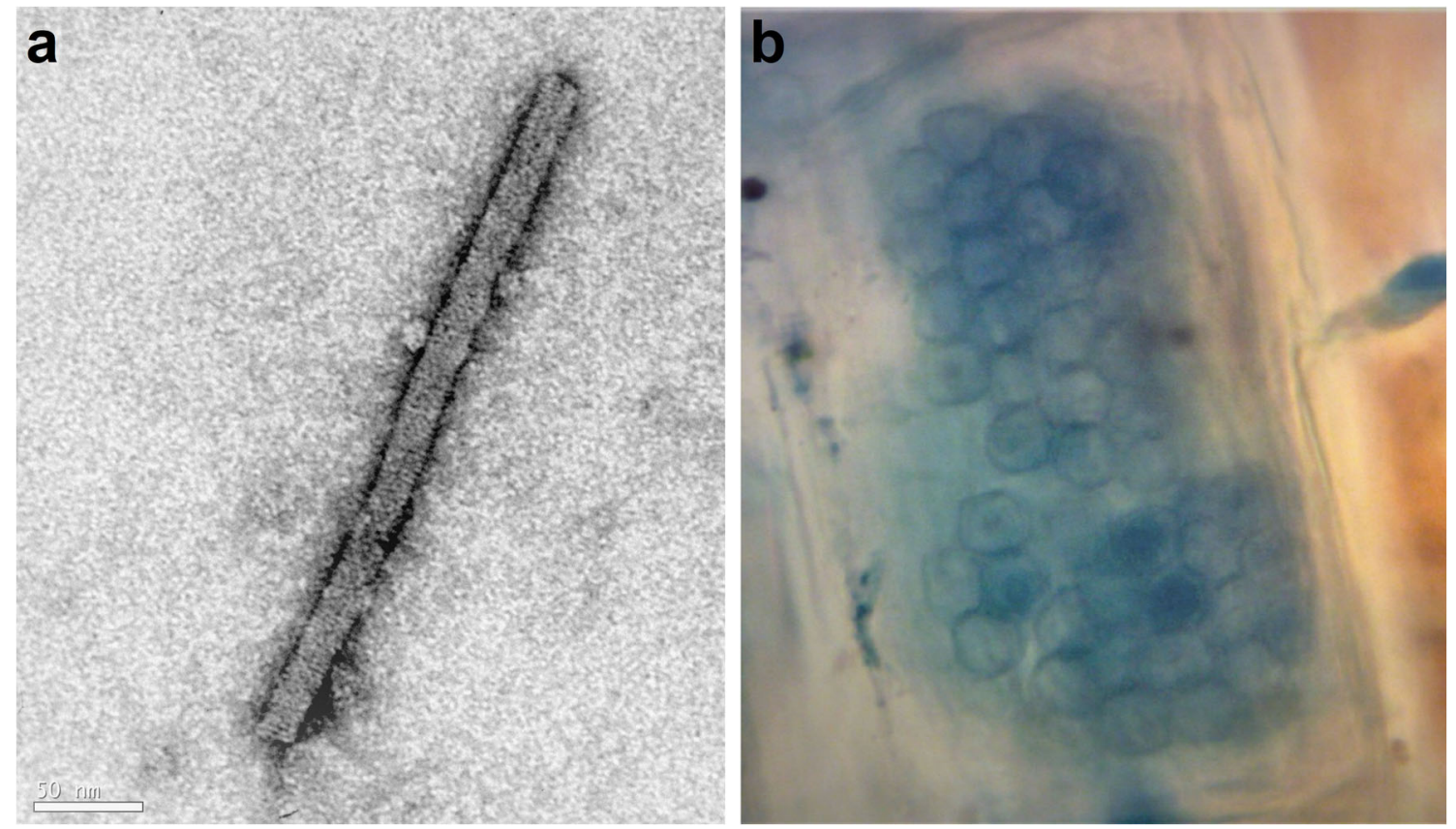

Fig. 2 a Negatively stained leaf extract, showing presumed WhSMV rod-shaped like-virus particle. b Resting spores of Polymyxa graminis in roots of symptomatic wheat plants stained with lactophenol 
FAO - Food and Agriculture Organization of the United Nations (2017) FAOSTAT Database. http://faostat3.fao.org/home/E. Accessed 30 May 2019

Kanyuka K, Ward E, Adams MJ (2003) Polymyxa graminis and the cereal viruses it transmits: a research challenge. Mol Plant Pathol 4(5):393-406
Valente JB, Pereira FS, Stempkowski LA, Farias M, Kuhnem P, Lau D, Fajardo TVM, Nhani Junior A, Casa RT, Bogo A, da Silva FN (2019) A novel putative member of the family Benyviridae is associated with soil-borne wheat mosaic disease in Brazil. Plant Pathol 68(3):588-600 